\title{
Cytotoxic Effects of Hellebrigenin and Arenobufagin Against Human Breast Cancer Cells
}

\author{
Yu Zhang ${ }^{1,2 t}$, Bo Yuan ${ }^{3 \star t}$, Baolin Bian ${ }^{2}$, Haiyu Zhao ${ }^{2}$, Anna Kiyomi ${ }^{4}$, Hideki Hayashi ${ }^{1}$, \\ Yui Iwatani ${ }^{1}$, Munetoshi Sugiura ${ }^{4}$ and Norio Takagi ${ }^{1 *}$ \\ 1 Department of Applied Biochemistry, Tokyo University of Pharmacy \& Life Sciences, Hachioji, Japan, 2 Institute of Chinese \\ Materia Medica, China Academy of Chinese Medical Sciences, Beijing, China, ${ }^{3}$ Laboratory of Pharmacology, School of \\ Pharmacy, Faculty of Pharmaceutical Sciences, Josai University, Sakado, Japan, ${ }^{4}$ Department of Drug Safety and Risk \\ Management, Tokyo University of Pharmacy \& Life Sciences, Hachioji, Japan
}

\section{OPEN ACCESS}

Edited by:

Maria Rosaria De Miglio,

University of Sassari, Italy

Reviewed by:

Melanie Coombs,

Acadia University, Canada

Chun Wai Mai,

International Medical University,

Malaysia

Muhammad Khan,

University of the Punjab, Pakistan

*Correspondence:

Bo Yuan

yuanbo@josai.ac.jp

Norio Takagi

takagino@toyaku.ac.jp

${ }^{t}$ These authors have contributed equally to this work

Specialty section: This article was submitted to Breast Cancer,

a section of the journal

Frontiers in Oncology

Received: 18 May 2021 Accepted: 05 August 2021 Published: 26 August 2021

Citation:

Zhang Y, Yuan B, Bian B, Zhao H, Kiyomi A, Hayashi H, Iwatani Y, Sugiura M and Takagi N (2021) Cytotoxic Effects of Hellebrigenin and Arenobufagin Against Human Breast Cancer Cells. Front. Oncol. 11:711220. doi: 10.3389/fonc.2021.711220
Development of new therapeutic strategies for breast cancer is urgently needed due to the sustained emergence of drug resistance, tumor recurrence and metastasis. To gain a novel insight into therapeutic approaches to fight against breast cancer, the cytocidal effects of hellebrigenin (Helle) and arenobufagin (Areno) were investigated in human estrogen receptor (ER)-positive breast cancer cell line MCF-7 and triple-negative breast cancer cell line MDA-MB-231. Helle exhibited more potent cytotoxicity than Areno in both cancer cells, and MCF-7 cells were more susceptible to both drugs in comparison with MDA-MB-231 cells. Apoptotic-like morphological characteristics, along with the downregulation of the expression level of $\mathrm{BCl}-2$ and $\mathrm{BCl}-\mathrm{xL}$ and the upregulation of the expression level of Bad, were observed in Helle-treated MCF-7 cells. Helle also caused the activation of caspase-8, caspase-9, along with the cleavage of poly(ADP-ribose) polymerase in MCF-7 cells. Helle-mediated necrosis-like phenotype, as evidenced by the increased propidium iodide (PI)-positive cells was further observed. $G_{2} / M$ cell cycle arrest was also induced by Helle in the cells. Upregulation of the expression level of p21 and downregulation of the expression level of cyclin D1, cyclin E1, cdc25C and survivin were observed in MCF-7 cells treated with Helle and occurred in parallel with $\mathrm{G}_{2} / \mathrm{M}$ arrest. Autophagy was triggered in MCF-7 cells and the addition of wortmannin or 3-MA, two well-known autophagy inhibitors, slightly but significantly rescued the cells. Furthermore, similar alterations of some key molecules associated with the aforementioned biological phenomena were observed in MDA-MB-231 cells. Intriguingly, the numbers of PI-positive cells in Helle-treated MCF-7 cells were significantly reduced by wortmannin and 3-MA, respectively. In addition, Helle-triggered $\mathrm{G}_{2} / \mathrm{M}$ arrest was significantly corrected by wortmannin, suggesting autophagy induction contributed to Helle-induced cytotoxicity of breast cancer cells by modulating necrosis and cell cycle arrest. Collectively, our results suggested potential usefulness of both Helle and Areno in developing therapeutic strategies to treat patients with different types of breast cancer, especially ER-positive breast cancer.

Keywords: breast cancer cells, hellebrigenin, arenobufagin, apoptosis, necrosis, $G_{2} / M$ arrest, autophagy 


\section{INTRODUCTION}

According to estimates from the World Health Organization (WHO) in 2020, female breast cancer has surpassed other cancer types as the most commonly diagnosed cancer, with an estimated 2.3 million new cases (1). Estrogen receptor (ER), progesterone receptor (PR) and human epidermal growth factor receptor-2 (HER2) are the most important prognostic and predictive markers for determining the appropriate breast cancer treatment $(2,3)$. Despite recent advances in early detection, diagnosis, and targeted treatment options such as Herceptin (trastuzumab), breast cancer remains a major health problem and is still the leading cause of cancer death in women worldwide $(1,2)$. Thus, the development of new therapeutic strategies is urgently needed for the treatment of breast cancer.

Given inseparable relationship between cancer development and inflammation, many anticancer agents have been well characterized by their anti-inflammatory and anticancer activity (4-6). Cinobufacini (also known as Huachansu), a well-known traditional Chinese medicine that comes from the dried skin of Bufo bufo gargarizans Cantor, has long been successfully used in clinic as anti-inflammatory and anticancer agents in China (7-9). In line with previous reports, we recently demonstrated that indolealkylamines, a kind of important hydrophilic ingredients of cinobufacini, exhibited protective effect on LPS-induced inflammation in zebrafish $(10,11)$. Bufadienolides are another kind of important effective constituents of cinobufacini, and we also demonstrated that active bufadienolide compounds such as gamabufotalin, hellebrigenin (Helle) and arenobufagin (Areno) exhibited selective cytocidal effects against intractable cancer cells (1214). Furthermore, we recently demonstrated that clinically achieved concentrations of trivalent arsenic derivative ( $\mathrm{As}{ }^{\mathrm{III}}$ ) combined with gamabufotalin exhibited synergistic cytotoxicity against glioblastoma cell line U-87, whereas showed much less cytotoxicity to human normal peripheral blood mononuclear cells (PBMCs) (15). These findings thus provide fundamental insight into the mechanisms underlying the anti-inflammatory and anticancer activity of cinobufacini. Although Deng et al. have demonstrated that Areno inhibits the growth of a human breast cancer cell line MCF-7 by inducing apoptosis associated with JNK signaling pathway (16), the cytocidal effects of Helle and Areno against breast cancer cells as well as the underlying molecular mechanisms remain largely unexplored.

Apoptosis has been characterized by several morphologic features including cell shrinkage and chromatin condensation, all of which are linked to the activation of caspases and their downstream molecules such as poly(ADP-ribose) polymerase (PARP) $(17,18)$. The activation of caspase- 8 and caspase- 9 has been closely linked to two major apoptotic machinery, known as the extrinsic and intrinsic apoptotic pathway, respectively (17, 18). A series of Bcl-2 family members, including anti-apoptotic effectors such as Bcl-2/Bcl-xL, and pro-apoptotic effectors such as $\mathrm{Bax} / \mathrm{Bad}$, have been demonstrated to regulate apoptosis by modulating mitochondrial membrane permeabilization $(18,19)$. On the other hand, necrosis has also linked to anticancer activity of chemotherapeutic agents, and has received considerable attention for the treatment of apoptosis-resistant cancer cells, in which apoptotic pathway is suppressed or absent (20). Cell cycle arrest has been viewed as one of major underlying mechanisms for the cytotoxicity of various anticancer drugs. Cell cycle is known to be sophisticatedly controlled by cyclindependent kinases $(\mathrm{CDK})$ paired with their respective cyclin binding partners (CDK/Cyclin complexes) $(14,21,22)$. The alteration of p21 Waf1/Cip1 (p21) and p27 Kip1 (p27), known as inhibitors for CDK/Cyclin complexes, also closely links to cell cycle arrest (21-24). Cdc25C, a member of cdc25 family, is known to be associated with cell cycle transition by modulating cdc2/Cyclin B1 $(14,25)$. Moreover, survivin is highly expressed in most human cancer cells and implicated in cell cycle transitions $(12,14,26)$. Besides, induction of autophagic cell death has emerged as a critical mechanism underlying cytocidal effect of various anticancer drugs $(12,14,15)$. Although previous studies have demonstrated that the cytotoxicity of some bufadienolide compounds such as Helle and Areno are attributed to the induction of either of apoptosis/necrosis, cell cycle arrest and autophagy in hepatoma and glioblastoma cells $(12,27,28)$, whether and how these biological phenomena contribute to the cytocidal effects of Helle and Areno in human breast cancer cells remain to be seen.

In this study, cytocidal effects of Helle and Areno were investigated in the human ER-positive breast cancer cell line MCF-7 and triple-negative breast cancer cell line MDA-MB-231, by focusing on growth inhibition associated with apoptosis/ necrosis, cell cycle arrest and autophagic cell death. Key regulatory molecules involved in the above-mentioned biological phenomena were evaluated to further elucidate the underlying mechanisms. Wortmannin and 3-methyladenine (3MA), two well-known autophagy inhibitors, were also employed to evaluate the correlation between autophagy and apoptosis/ necrosis as well as cell cycle transition.

\section{MATERIALS AND METHODS}

\section{Materials}

Hellebrigenin (Helle) ( $\geq 98 \%$ purity) and arenobufagin (Areno) ( $\geq 98 \%$ purity) were purchased from Baoji Herbest Bio-Tech Co., Ltd. (Baoji, China). Fetal bovine serum (FBS) and HEPES were purchased from Sigma Chemical Co. (St. Louis, MO, USA). RPMI-1640 and DMEM medium, 3-methyladenine (3-MA) and wortmannin were obtained from Wako Pure Chemical Industries (Osaka, Japan). 25\% glutaraldehyde solution were purchased from Kanto chemical CO., INC. (Tokyo, Japan). WST-1 and 1-Methoxy PMS were obtained from Dojindo Molecular Technologies, Inc. (Tokyo, Japan). Propidium iodide (PI), ribonuclease A (RNaseA), crystal violet (C.I. 42555) Certistain ${ }^{\circledR}$ were purchased from Merck KGaA (SigmaAldrich; Darmstadt, Germany).

\section{Cell Culture and Treatment}

Human breast cancer cell line MCF-7 and MDA-MB-231 were obtained from the American Type Culture Collection (ATCC, Manassas, VA, USA). MCF-7 and MDA-MB-231 were cultured 
in RPMI-1640 and DMEM medium (high glucose) supplemented with $10 \%$ heat-inactivated FBS and antibiotics (100 U/ml of penicillin and $100 \mu \mathrm{g} / \mathrm{ml}$ of streptomycin (Wako Pure Chemical Industries)) in a humidified $5 \% \mathrm{CO}_{2}$ atmosphere at $37^{\circ} \mathrm{C}$, respectively. In experiments using inhibitors, MCF-7 and MDA-MB-231 cells were treated with respective inhibitor at the indicated concentrations for 30 min prior to treatment with indicated concentrations of Helle, in the presence or absence of respective inhibitor for an additional $48 \mathrm{~h}$. Helle and Areno were dissolved in dimethyl sulfoxide (DMSO), and no cytotoxicity of the final concentrations of DMSO $(0.02 \%)$ was observed in the current experimental system.

\section{Cell Viability and Clonogenic Survival}

Following treatment for $48 \mathrm{~h}$ with various concentrations of Helle, cell viability was measured by the WST-1 assay as described previously (29). The relative cell viability was expressed as the ratio of the absorbance of each treatment group against those of the corresponding untreated control group. The $\mathrm{IC}_{50}$ values of the drugs were calculated using GraphPad Prism ${ }^{\circledR} 7$ software. With respect to the morphological alterations of U-87 cells, the cells were imaged using an inverted microscope (CKX53; Olympus Corporation, Tokyo, Japan) fitted with a digital camera following treatment with various concentrations (3, 10, 30 and 100 $\mathrm{nM}$ ) of Helle for $48 \mathrm{~h}$. Clonogenic survival assays were performed according to the methods previously described with slight modifications (12, 14, 24). Briefly, MCF-7 and MDA-MB-231 cells were seeded at 2,000 cells/well in 12-well plates, and treated for $24 \mathrm{~h}$ with various concentrations $(1,3,10,30,100,300$ and 1000 $\mathrm{nM}$ ) of Helle and Areno, respectively. The medium was then replaced with fresh media and the cells were allowed to grow for $7-10$ days in a humidified $5 \% \mathrm{CO}_{2}$ atmosphere at $37^{\circ} \mathrm{C}$. Then, the cells were fixed with $0.25 \%$ glutaraldehyde/PBS for $15 \mathrm{~min}$ prior to staining with $0.2 \%$ crystal violet/PBS for $10 \mathrm{~min}$ at room temperature. Following washout of extra crystal violet with water to get an adequate staining pattern, the images of crystal violetstained cells were scanned into a computer, followed by dissolution of the violet-stained cells in $1 \%$ SDS. The absorbance of the cell lysates was determined at $550 \mathrm{~nm}$. The relative colony formation rate was expressed as the ratio of the absorbance at $550 \mathrm{~nm}$ of each treatment group against those of the corresponding untreated control group.

\section{Hoechst33342/PI Double Staining Assay}

The phenotypic features of cell death were evaluated by use of Hoechst33342/PI double staining assay. After treatment for $48 \mathrm{~h}$ with different concentrations (3, 10, 30 and $100 \mathrm{nM}$ ) of Helle, MCF-7 cells were washed twice with cold PBS, followed by incubation with $100 \mu \mathrm{l}$ of staining solution $(3 \mu \mathrm{l} / \mathrm{ml}$ of PI and $0.05 \%$ Hoechst in PBS) for $15 \mathrm{~min}$ at room temperature. The staining images were captured using a BZ-X800 Keyence fluorescence microscope (Keyence, Osaka, Japan) and Leica X software at $100 \times$ magnification (Leica, Tokyo, Japan).

\section{Cell Cycle Analysis}

After treatment of MCF-7 cells with various concentrations of Helle (10, 30 and $100 \mathrm{nM}$ ) for $48 \mathrm{~h}$, cell cycle analysis was performed using a FACS Canto ${ }^{\text {TM }}$ flow cytometer (Becton Dickinson, CA, USA) according to the methods reported previously $(14,15,30)$. Briefly, cells were washed twice with cold PBS, fixed with $1 \%$ paraformaldehyde/PBS on ice for 30 min, washed twice again with cold PBS, permeabilized in $70 \%(\mathrm{v} /$ v) cold ethanol and kept at $-20^{\circ} \mathrm{C}$ for at least $4 \mathrm{~h}$. The cell were then incubated with $0.25 \%$ Triton-X 100 for 5 min on ice. After centrifugation $\left(430 \times \mathrm{g}\right.$ for $5 \mathrm{~min}$ at $\left.4^{\circ} \mathrm{C}\right)$ and washing with $\mathrm{PBS}$, cells were resuspended in $500 \mu \mathrm{l}$ of PI/RNase A/PBS $(5 \mu \mathrm{g} / \mathrm{ml}$ of $\mathrm{PI}$ and $0.1 \%$ RNase A in PBS) and incubated for $30 \mathrm{~min}$ in the dark at room temperature. A total of 10,000 events were acquired, and FACSDiva ${ }^{\mathrm{TM}}$ software (v6.0; BD Biosciences) and ModFit LT ${ }^{\mathrm{TM}}$ v3.0 (Verity Software House, Inc., Topsham, ME, USA) were used to calculate the number of cells at each $\mathrm{G}_{0} /$ $G_{1}, S$ and $G_{2} / M$ phase fraction.

\section{Western Blot Analysis}

For preparation of the protein samples, cell pellets $\left(1-2 \times 10^{6}\right.$ cells per $110 \mu \mathrm{l}$ buffer) were suspended in Laemmli buffer containing protease inhibitor cocktail tablets (Roche Diagnostics Co., Mannheim, Germany). Protein concentrations of the supernatant were determined according to Bradford's method using the Protein Assay Dye Reagent Concentrate (Bio-Rad Laboratories, Inc.), according to the manufacturer's instructions, using BSA as the standard. Western blot analysis was carried out according to the method previously described $(14,15)$. Protein bands were detected using the following primary antibodies: Mouse anti-human $\beta$-actin (cat. no. A-5441; Sigma-Aldrich; Merck KGaA, Darmstadt, Germany), mouse anti-human Bcl-2 (cat. no. 12741), rabbit anti-human Bcl-xL (cat. no. 2764), rabbit anti-human Bax (cat. no. 2772), rabbit anti-human Bad (cat. no. 9292), mouse anti-human caspase 8 (cat. no. 9746), rabbit antihuman caspase 9 (cat. no. 9502), rabbit anti-human PARP (cat. no. 9542), mouse anti-human p21 (cat. no. 2946), rabbit antihuman p27 (cat. no. 2552), rabbit anti-human cyclin B1 (cat. no. 4135), rabbit anti-human cyclin D1 (cat. no. 2978), rabbit antihuman cyclin E1 (cat. no. 20808), rabbit anti-human Cdc25c (cat. no. 4688), mouse anti-human survivin (cat. no. 2802), rabbit antihuman LC3A/B (cat. no. 12741), rabbit anti-human p-AMPK $\alpha$ (cat. no. 2537), rabbit anti-human AMPK $\alpha$ (cat. no. 2532; all from Cell Signaling Technology, Inc., Danvers, MA, USA)). Blotted protein bands were detected with respective horseradish peroxidase-conjugated secondary antibody (anti-mouse IgG, cat. no. A5906; anti-rabbit IgG, cat. no. A0545; both from SigmaAldrich; Merck KGaA) and an appropriate enhanced chemiluminescence (ECL) Western Blot detection kits [(ImmunoStar basic and ImmunoStar zeta (FUJIFILM Wako, Osaka, Japan) or West Femto (Pierce Biotechnology, Thermo Fisher, MA, USA)]. Relative amounts of the immunoreactive proteins obtained were subsequently quantitatively analyzed with the ImageJ software program (Rasband, W.S., ImageJ, U. S. National Institutes of Health, Bethesda, Maryland, USA, http://rsb. info.nih.gov/ij/).

\section{Statistical Analysis}

Experiments were independently repeated three times, and the results were shown as the means \pm standard deviation $(\mathrm{SD})$ of 
three assays. The Student's t-test was used to compare sample means from two groups, and one-way ANOVA followed by Dunnett's post hoc test was used to compare sample means from more than three groups. A probability level of $p<0.05$ was considered to indicate a statistically significant difference.

\section{RESULTS}

\section{Cytotoxic Effects of Helle and Areno Against Human Breast Cancer Cell Lines MCF-7 and MDA-MB-231}

A significant decrease in cell viability was observed in a dosedependent manner in MCF-7 and MDA-MB-231 cells after treatment with various concentrations of Helle for $48 \mathrm{~h}$, and its $\mathrm{IC}_{50}$ value was $34.9 \pm 4.2 \mathrm{nM}$ and $61.3 \pm 9.7 \mathrm{nM}$, respectively (Figures 1B, C). A similar dose-dependent growth inhibition was also observed in both cells after treatment with various concentrations of Areno for $48 \mathrm{~h}$, and its $\mathrm{IC}_{50}$ value was $48.5 \pm$ $6.9 \mathrm{nM}$ and $81.2 \pm 10.3 \mathrm{nM}$, respectively (Figures 1B, C). These results indicated that the cytotoxicity of Helle was more potent than Areno, and that MCF-7 cells were more sensitive to the cytotoxicity of both Helle and Areno, compared to MDA-MB231 cells.

\section{Inhibition of Colony Formation of MCF-7 and MDA-MB-231 Cells by Helle and Areno}

A colony formation assay was conducted to evaluate whether exposure to Helle and Areno suppressed the surviving fraction of MCF-7 and MDA-MB-231 cells. As shown in Figure 2, significant suppression of the colony numbers of MCF-7 and
MDA-MB-231 cells was observed after long-term treatment with Helle at concentrations starting from $30 \mathrm{nM}$ and $10 \mathrm{nM}$, respectively. In comparison, an inhibitory activity against colony formation of both cells was observed in Areno even at the concentrations as low as $10 \mathrm{nM}$. These results indicated the superior potency of Helle and Areno against the survival of both MCF-7 and MDA-MB-231 cells.

\section{Phenotypic Features of Cell Death in MCF-7 Cells Treated by Helle}

Due to the potent cytotoxic effect of Helle and higher susceptibility of MCF-7 cells to the drug (Figure 1), the mechanism underlying its cytotoxicity was thus further evaluated in the cells. Following treatment for $48 \mathrm{~h}$ with various concentrations of Helle (3, 10, 30 and $100 \mathrm{nM})$, which were determined according to its $\mathrm{IC}_{50}$ value, the phenotypic features of cell death were evaluated by use of Hoechst33342/PI staining assay. As shown in Figure $\mathbf{3}$ and Supplementary Figure 1, following exposure to $10 \mathrm{nM}$ Helle, a non-negligible number of MCF-7 cells showing exclusively apoptotic-like morphology, characterized by cell shrinkage, chromatin condensation as evidenced by a clear increase in the fluorescence intensity of Hoechst33342 in comparison with control group, were observed, although a clear alteration was not recognized after treatment with $3 \mathrm{nM}$ Helle. Intriguingly, a small portion of PI-positive cells were observed after treatment with Helle even at the concentrations as low as $3 \mathrm{nM}$, indicating that Helle-triggered cytotoxicity was also associated with a necrosis-like phenotype in the cells. Furthermore, these phenomena associated with apoptosis and/or necrosis-like phenotype became more evident when the concentrations were greater than $30 \mathrm{nM}$.
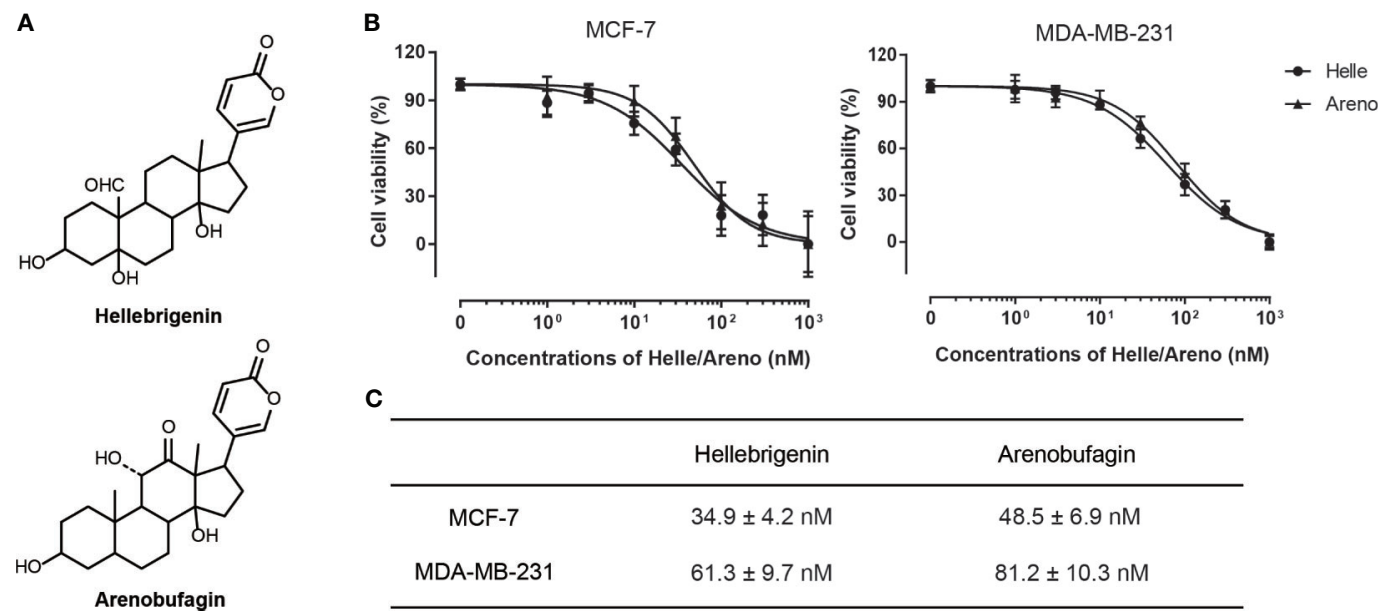

C

\begin{tabular}{cll}
\hline & Hellebrigenin & Arenobufagin \\
\hline MCF-7 & $34.9 \pm 4.2 \mathrm{nM}$ & $48.5 \pm 6.9 \mathrm{nM}$ \\
MDA-MB-231 & $61.3 \pm 9.7 \mathrm{nM}$ & $81.2 \pm 10.3 \mathrm{nM}$ \\
\hline
\end{tabular}

FIGURE 1 | Cytotoxic effects of Helle and Areno against human breast cancer cell lines MCF-7 and MDA-MB-231. Chemical structures of Helle and Areno (A). Cell viability was determined by WST-1 assay after treatment of MCF-7 or MDA-MB-231 (B) with various concentrations of Helle and Areno (1, 3, 10, 30, 100, 300 and $1000 \mathrm{nM}$ ) for $48 \mathrm{~h}$. Relative cell viability was calculated as the ratio of the absorbance at $450 \mathrm{~nm}$ of each treatment group against those of the corresponding untreated control group. The $I \mathrm{I}_{50}$ values of the drugs were calculated using GraphPad Prism ${ }^{\circledR} 7$ software (C). Data are shown as the means \pm SD from more than three independent experiments. 

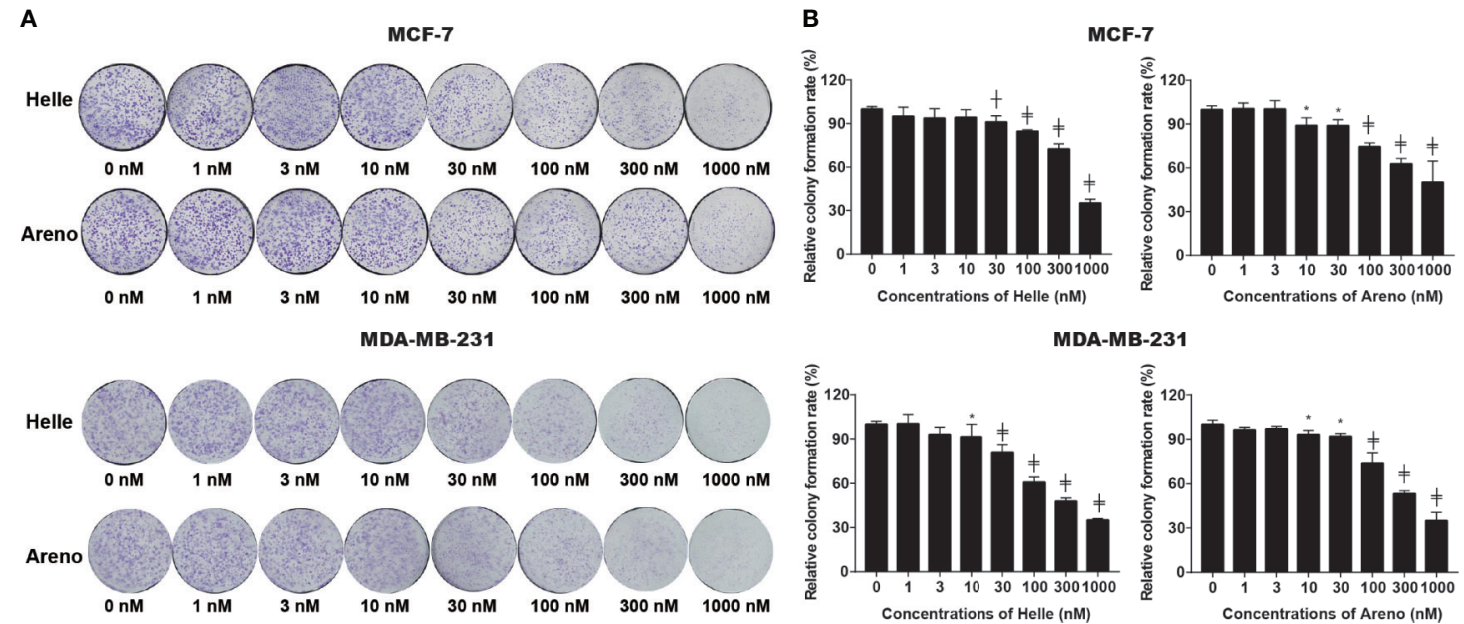

FIGURE 2 | Inhibition of colony formation of MCF-7 and MDA-MB-231 cells by Helle and Areno. The cells were seeded at 2,000 cells/well in 12-well plates following treatment with indicated concentrations (1, 3, 10, 30, 100, 300 and $1000 \mathrm{nM}$ ) of Helle and Areno for $24 \mathrm{~h}$. Representative images of the clonogenic assays are shown from three independent experiments (A). The relative colony formation rate was expressed as the ratio of the absorbance at $550 \mathrm{~nm}$ of each treatment group against those of the corresponding untreated control group as described in Materials and methods (B). Data are shown as means \pm SD from three independent experiments. ${ }^{*} p<0.05 ;{ }^{+} p<0.01 ;{ }^{*} p<0.0001$ vs. control. Helle, hellebrigenin; Areno, arenobufagin.
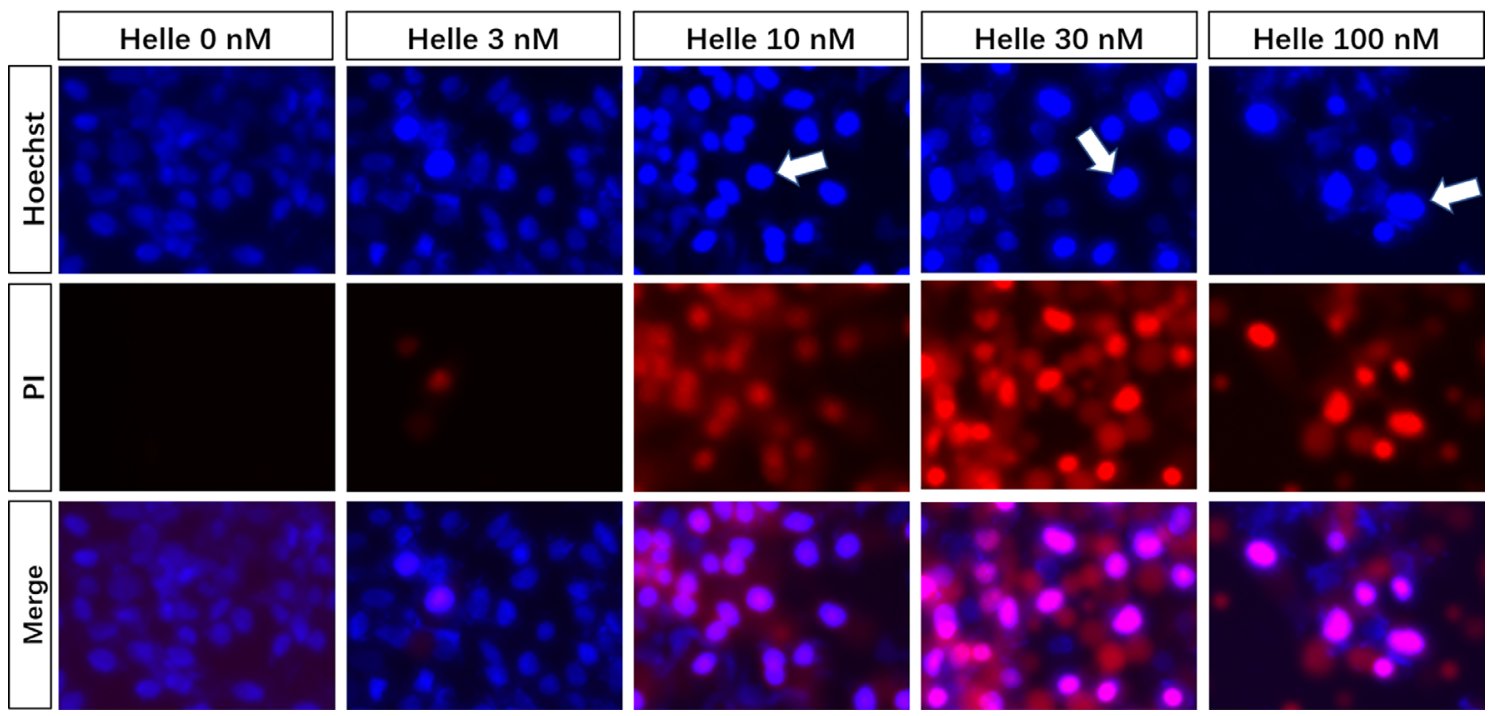

FIGURE 3 | Phenotypic features of cell death in MCF-7 cells treated by Helle. After treatment with various concentrations of Helle (3, 10,30 and 100 nM) for 48 h, the phenotypic features of cell death were evaluated using the Hoechst 33342 (blue)/PI (red) staining as described in Materials and methods. Cells with condensed nuclei (arrows) and red fluorescence were identified as those undergoing apoptosis and necrosis, respectively. The pink fluorescence represents the merged images of Hoechst 33342 and PI. Images were captured using a BZ-X800 Keyence fluorescence microscope and Leica X software at $100 \times$ magnification. Helle, hellebrigenin.

\section{Helle-Mediated Activation of Apoptosis Signaling Pathway in MCF-7 Cells}

Commitment of cells to apoptosis is closely regulated by Bcl-2 (B-cell leukemia/lymphoma) family, including anti-apoptotic effectors such as Bcl-2/Bcl-xL, and pro-apoptotic effectors such as Bax/Bad (19). As shown in Figure 4, in comparison to control group, a dose-dependent downregulation of the expression level of $\mathrm{Bcl}-2$ and Bcl-xL was induced by Helle. Coincidentally, a dosedependent upregulation of the expression level of Bad was observed in Helle-treated MCF-7 cells, although almost no significant alteration in the expression level of Bax was detected. At the same time, the exposure to Helle caused a significant downregulation of 

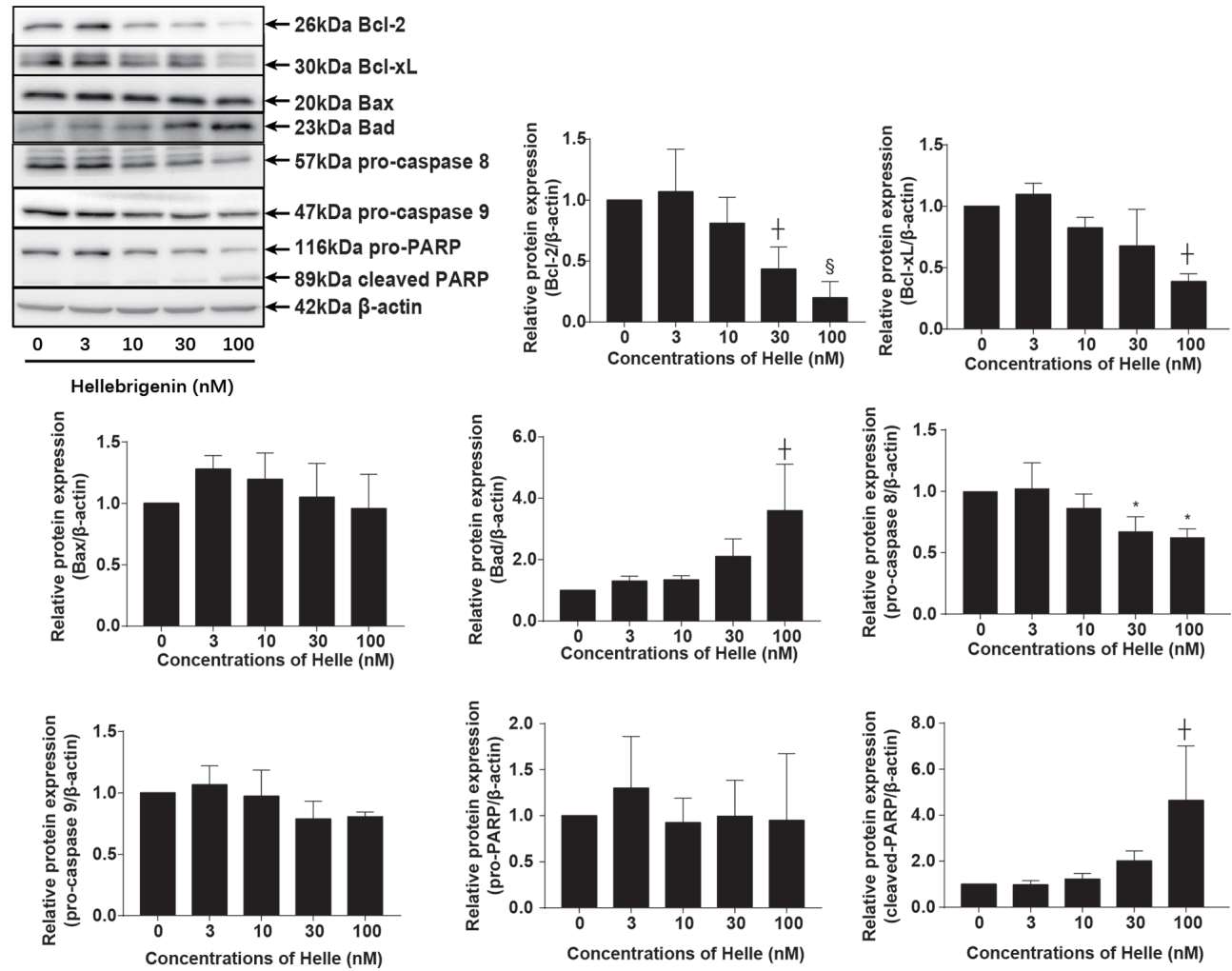

FIGURE 4 | Helle-mediated activation of apoptosis signaling pathway in MCF-7 cells. After treatment with various concentrations of Helle (3, 10,30 and 100 nM) for $48 \mathrm{~h}$, the expression profile of apoptosis-related proteins was analyzed using western blotting. The relative expression levels were expressed as the ratios between each target gene protein and $\beta$-actin protein expression levels, and compared with those of untreated control group, respectively. Data are presented as the means \pm SD from three independent experiments. ${ }^{\star} p<0.05 ;{ }^{+} p<0.01 ;{ }^{\S} p<0.001$ vs. control.

the expression of pro-caspase- 8 , which was accompanied by a trend towards downregulation of the expression of pro-caspase-9, indicating the activation of caspase- 8 and caspase-9. Furthermore, cleavage of PARP, known as an early marker of chemotherapyinduced apoptosis (31), was observed concomitantly, indicating the onset of apoptosis. In addition, similar downregulation of the expression levels of $\mathrm{Bcl}-2, \mathrm{Bcl}-\mathrm{xL}$, as well as pro-caspase- 8 and -9 was also observed in MDA-MB-231 cells treated by Helle (Supplementary Figure 2).

\section{Effect of Helle on the Cell Cycle Profiling and the Expression Level of Cell Cycle Related-Proteins in MCF-7 Cells}

To investigate whether cell cycle arrest is implicated in the cytocidal effect of Helle, cell cycle analyses were carried out using flow cytometry following treatment with various concentrations of Helle for $48 \mathrm{~h}$. As shown in Figure 5, in comparison to control group, a modest increase in the number of cells in the $G_{2} / M$ phase along with a significant decrease in the number of cells in the S phase was observed in MCF-7 cells treated with Helle at the concentration starting from $30 \mathrm{nM}$. An increase in the number of cells in the $G_{2} / M$ phase was further strengthened following exposure to $100 \mathrm{nM}$ Helle. Concomitantly, a significant decrease in the number of cells in $\mathrm{G}_{0} / \mathrm{G}_{1}$ and $S$ phase was also observed. In addition, similar $\mathrm{G}_{2} / \mathrm{M}$ arrest was also observed in MDA-MB-231 cells following treatment for $48 \mathrm{~h}$ with $60 \mathrm{nM}$ Helle, which was almost equal to its $\mathrm{IC}_{50}$ value of the cells (Supplementary Figure 3).

Upregulation of p21 and p27 has been demonstrated to be involved in $\mathrm{G}_{2} / \mathrm{M}$ arrest induced by anticancer agents in different types of cancer cells including breast cancer $(23,24,30)$. As shown in Figure 6, in line with these previous reports, a significant increase in the expression level of p21 was observed in MCF-7 cells treated with Helle at the concentration starting from $10 \mathrm{nM}$, although the magnitude of increase was different according to different drug doses. Surprisingly, downregulation of the expression level of p27 was observed in the treated cells, indicating its little involvement in Helle-mediated $\mathrm{G}_{2} / \mathrm{M}$ arrest. In addition, downregulation of the expression level of cyclin D1, cyclin E1 and cdc25C was observed in Helle-treated MCF-7 cells in a dose-dependent manner, whereas almost no alteration of cyclin B1 expression was detected. Of note, the exposure to Helle at the concentrations greater than $10 \mathrm{nM}$ potently downregulated the expression level of survivin. Furthermore, similar downregulation of the expression level of cyclin D1, cyclin E1 as well as cdc25C was observed in Helletreated MDA-MB-231 cells (Supplementary Figure 4). 

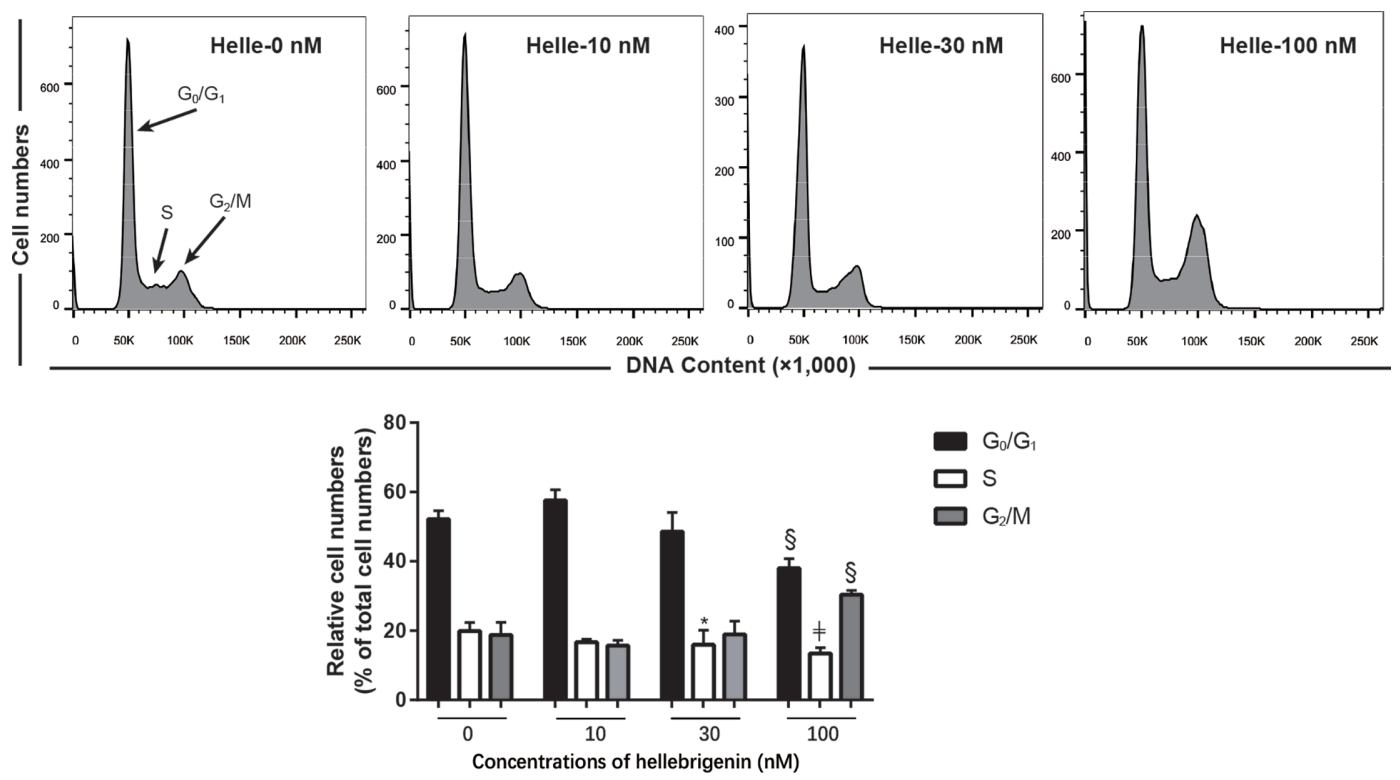

FIGURE 5 | Effect of Helle on the cell cycle profiling in MCF-7 cells. After treatment with various concentrations of Helle (10, 30 and $100 \mathrm{nM}$ ) for 48 h, cell cycle analysis was performed using a FACS Canto flow cytometer as described in Materials and methods. A representative FACS histogram from three independent experiments is shown. ModFit $L T^{T M}$ v3.0 was used to calculate the number of cells at each $G_{0} / G_{1}, S$ and $G_{2} / M$ phase fraction. Results are shown as the means \pm SD from three independent experiments. ${ }^{*} p<0.05 ;{ }^{\S} p<0.001 ;{ }^{*} p<0.0001$ vs. control. Helle, hellebrigenin.

\section{Involvement of Autophagic Cell Death in Helle-Triggered Cytotoxicity in MCF-7 Cells}

Many anticancer agents have been characterized as inducers of autophagy $(14,24,30)$, and LC3 has been well known as an established autophagy marker (32, 33). As shown in Figure 7A, a modest upregulation of the expression level of LC3 was clearly induced by the treatment with $10 \mathrm{nM}$ Helle compared to control group. Furthermore, exposure to $30 \mathrm{nM}$ Helle significantly upregulated the expression level of LC3. Surprisingly, the magnitude expression level of LC3 dropped when the concentrations of Helle increased up to $100 \mathrm{nM}$. The drop might be due to the degradation of LC3, as a result of intensive cytotoxicity of $100 \mathrm{nM}$ Helle, although further investigation is obviously needed. Additionally, a similar upregulation of the expression level of LC3 was also observed in MDA-MB-231 cells treated by Helle (Supplementary Figure 5). AMP-activated protein kinase (AMPK), a key energy sensor, has been shown to be an upstream promoter of autophagy induction $(32,34)$. In this regard, a dose-dependent increase in the expression level of phospho-AMPK over the endogenous level was detected in the treated cells, and a statistically significant increase in its expression was further observed in $100 \mathrm{nM}$ Helle-treated cells (Figure 7B). Moreover, almost no change in the expression level of total AMPK expression was observed (Figure 7B).

Next, two well-known autophagy inhibitor, wortmannin and 3-methyladenine (3-MA) were employed to evaluated whether the induction of autophagy contributed to Helle-mediated cell growth inhibition. Consistent with Figure 1, Helle-triggered dose-dependent growth inhibition was reconfirmed in MCF-7 cells (Figures 7C, D). In comparison with control group, the addition of wortmannin significantly abrogated the cytotoxicity of $100 \mathrm{nM}$ Helle, although similar abrogation was not observed when treated with $30 \mathrm{nM}$ Helle (Figure 7C). Moreover, the addition of 3-MA rescued the cell from Helle-triggered toxicity, as evidenced by a modest but statistically significant increase in cell viability in the presence of 3-MA, although a slight growth inhibition was induced by 3-MA itself (Figure 7D).

\section{Correlation Between Autophagy and Apoptosis, Necrosis as Well as Cell Cycle Arrest in MCF-7 Cells Treated With Helle}

Therapeutic effects of anticancer drugs have been attributed to the crosstalk between apoptosis, necrosis and autophagy $(17,35)$. Wortmannin and 3-MA were thus employed to clarify whether there was a link between autophagy and apoptosis/necrosis as well as $\mathrm{G}_{2} / \mathrm{M}$ arrest in Helle-treated MCF-7. Consistent with Figure 3, apoptosis and necrosis, as evidenced by chromatin condensation and/or nuclei fragmentation, and the existence of PI-positive cells, were reconfirmed respectively in MCF-7 cells following the exposure to $30 \mathrm{nM}$ Helle for $48 \mathrm{~h}$ (Figure 8A). In comparison, the numbers of PI-positive cells were significantly reduced by the addition of either wortmannin or 3-MA. On the other hand, almost no alteration was observed in the morphological changes associated with apoptosis regardless of the presence of wortmannin or 3-MA, indicating little relation 

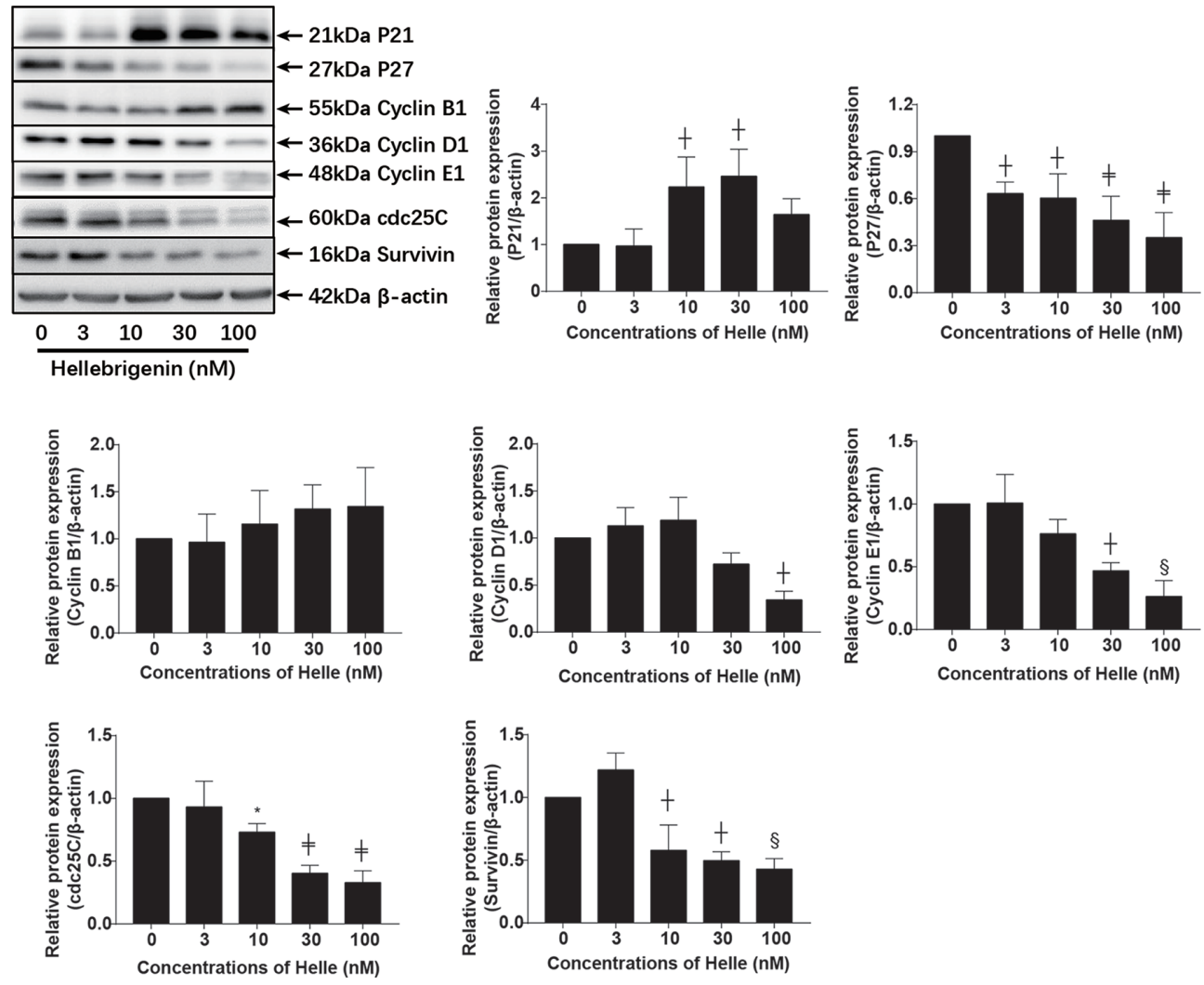

FIGURE 6 | Effect of Helle on the expression level of cell cycle related-proteins in MCF-7 cells. After treatment with various concentrations of Helle (3, 10, 30 and $100 \mathrm{nM}$ ) for $48 \mathrm{~h}$, the expression levels of cell cycle-related proteins were analyzed by western blotting. The relative expression levels were expressed as the ratios between each target gene protein and $\beta$-actin protein expression levels, and compared with those of untreated control group, respectively. Data are presented as the means \pm SD from three independent experiments. ${ }^{*} p<0.05 ;{ }_{p}<0.01 ;{ }^{\S} p<0.001 ;{ }^{\neq} p<0.0001$ vs. control.

between autophagy and apoptosis in Helle-treated MCF-7 cells. With respect to cell cycle arrest, $\mathrm{G}_{2} / \mathrm{M}$ phase arrest was confirmed in MCF-7 cells treated by $100 \mathrm{nM}$ Helle, accompanied by a significant decrease in the number of cells in $\mathrm{G}_{0} / \mathrm{G}_{1}$ and $\mathrm{S}$ phases (Figure 8B and Supplementary Figure 6). Again, Helle-triggered $\mathrm{G}_{2} / \mathrm{M}$-phase arrest was also successfully corrected by the addition of wortmannin.

\section{DISCUSSION}

Results from this study clearly demonstrated the cytotoxicity of Helle and Areno against human breast cancer cells, and further clarified that MCF-7 cells were more sensitive to the cytotoxicity of both compounds, compared to MDA-MB-231 cells. We have previously demonstrated that both Helle and Areno exhibit selective cytocidal effects against intractable cancer cells such as glioblastoma cell line U-87 and pancreatic cancer cell line SW1990, rather than noncancerous cells including human normal PBMCs (12-14), suggesting their broad-spectrum utility across different types of cancer cells. Given a clear difference between MCF-7 and MDA-MB-231 cells in terms of the expression level of ER $(24,30)$, our results further suggested potential usefulness of both Helle and Areno in developing therapeutic strategies to treat patients with different types of breast cancer, especially ER-positive breast cancer.

It has been demonstrated that high expression of steroid receptor coactivator 3 (SRC-3), known to play a critical role in mammary tumor development and metastasis $(36,37)$, is correlated with poor survival in ER-positive breast cancer patients $(38,39)$. A previous study has clarified that bufalin, one of active bufadienolide compounds with similar chemical structure with Helle and Areno, can function as a SRC-3 inhibitor by directly binding to SRC-3 in its receptor interacting domain and selectively promoting SRC-3 protein degradation in ER-positive breast cancer cell lines (40). Intriguingly, both bufalin and Areno have been demonstrated to suppress the proliferation and survival of HER2 overexpressing breast cancer cells, along with the declination of SRC-3 (41), although the effect of Helle on the expression level of SRC-3 still remains unknown. Taking these previous results and our observations into account, we thus suggest that the differential sensitivity of MCF-7 and MDA-MB-231 to both Helle and Areno could be attributed to the inhibitive effect of 

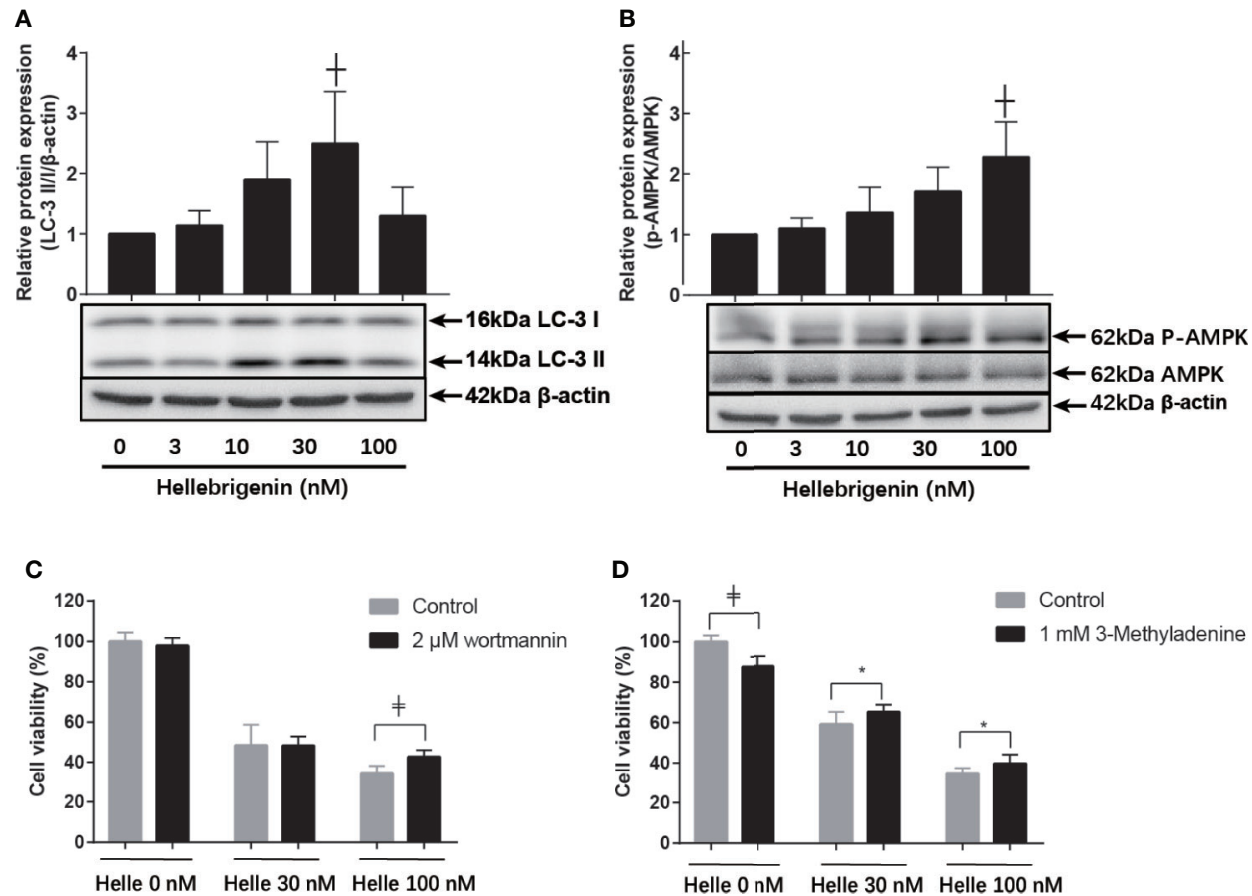

FIGURE 7 | Involvement of autophagic cell death in the cytotoxicity of MCF-7 cells treated with Helle. After treatment with various concentrations of Helle (3, 10,30 and $100 \mathrm{nM}$ ) for $48 \mathrm{~h}$, the expression levels of autophagy induction-related proteins were analyzed by western blotting (A, B). Cell viability was determined by WST1 assay after treatment for $48 \mathrm{~h}$ with Helle at the concentrations of 30 or $100 \mathrm{nM}$ in the absence or presence of $2 \mu \mathrm{M}$ wortmannin (C) and $1 \mathrm{mM} 3-\mathrm{MA}$ (D), respectively. Data are presented as the means \pm SD from three independent experiments. ${ }^{*} p<0.05 ;{ }^{+} p<0.01 ;{ }^{*} p<0.0001$ vs. control. Helle, hellebrigenin.

A
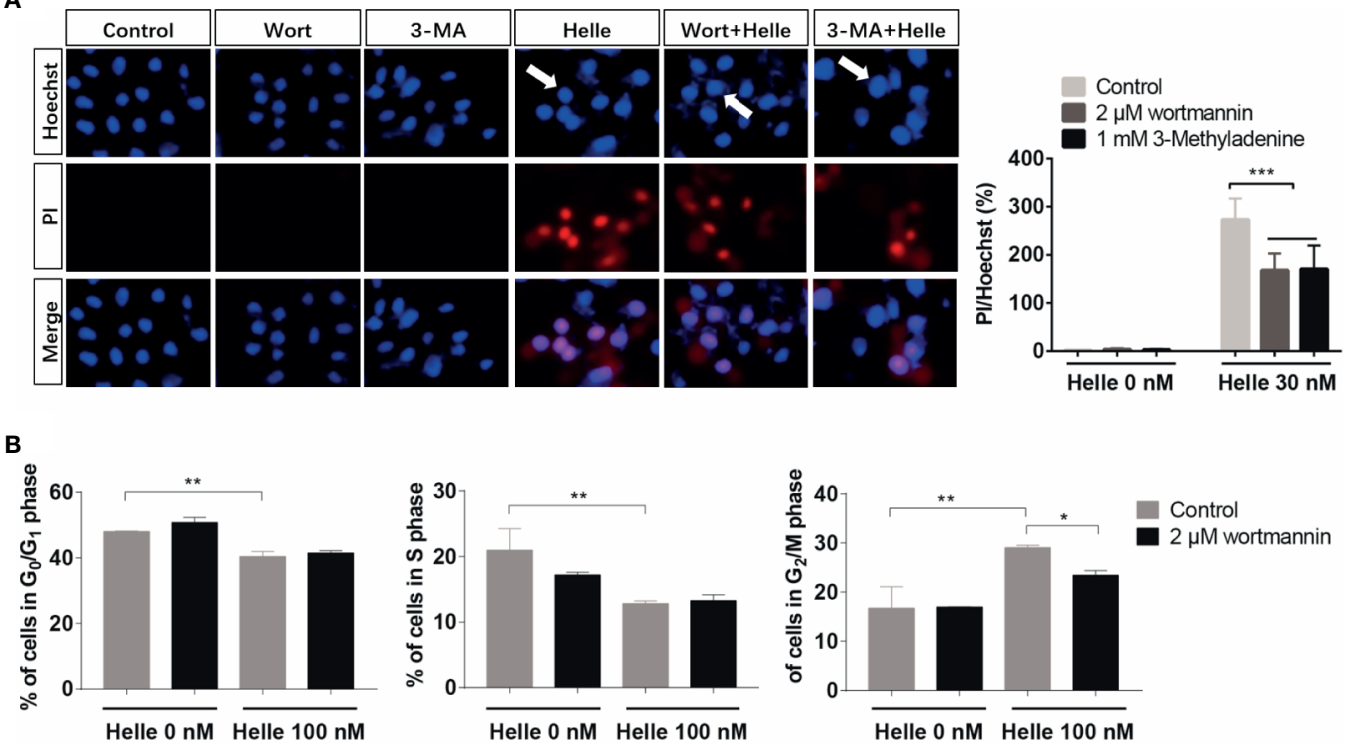

FIGURE 8 | Correlation between autophagy and apoptosis, necrosis as well as cell cycle arrest in MCF-7 cells treated with Helle. (A) After treatment for $48 \mathrm{~h}$ with $30 \mathrm{nM}$ Helle in the absence or presence of $2 \mu \mathrm{M}$ wortmannin or $1 \mathrm{mM} 3-\mathrm{MA}$, the phenotypic features of cell death were evaluated using the Hoechst 33342 (blue)/P (red) staining as described in Materials and methods. The pink fluorescence represents the merged images of Hoechst 33342 and PI. Images were captured using a BZ-X800 Keyence fluorescence microscope and Leica X software at 100xmagnification. (B) After treatment for $48 \mathrm{~h}$ with $100 \mathrm{nM}$ Helle in the absence or presence of $2 \mu \mathrm{M}$ wortmannin, cell cycle analysis was performed by the same manner as described in the legend of Figure $\mathbf{5}$. Data are presented as the means \pm SD from three independent experiments. ${ }^{*} \mathrm{p}<0.05$; ${ }^{* \star} \mathrm{p}<0.01$; ${ }^{\star \star *} \mathrm{p}<0.001$. Helle, hellebrigenin; Wort, wortmannin. 
both two compounds on SRC-3, although the alteration of the expression and activity of SRC-3 in breast cancer in vitro and in vivo obviously warrants further investigation to draw a solid conclusion.

The induction of apoptosis and/or necrosis in cancer cells has been closely linked to the cytocidal effect of anticancer reagents including bufadienolide compounds such as Helle and Areno $(12-14,16,27)$. In line with these previous reports, apoptotic-like morphological characteristics, along with the downregulation of $\mathrm{Bcl}-2$ and Bcl-xL expression and the upregulation of $\mathrm{Bad}$ expression, were observed in MCF-7 cells treated with Helle. Similar alterations were also observed in MDA-MB-231 cells. The activation of caspase- 8 and -9 as well as their downstream molecule, PARP, was further confirmed. Caspase- 8 and -9 have been established as key regulators of intrinsic and extrinsic apoptosis pathway, respectively $(18,22)$. Collectively, we suggested that apoptosis induction via the activation of intrinsic/extrinsic apoptotic signaling pathway contributed to Helle-triggered cytotoxicity of breast cancer cells. Additionally, in agreement with our previous reports showing the necrosisinducing activities of Helle against glioblastoma and pancreatic cancer cell lines $(12,13)$, induction of necrosis was also observed in MCF-7 cells. Given that tumor cells can evolve diverse strategies to evade apoptosis during tumor development (20, 42), the potential necrosis-inducing activities of Helle should be beneficial to treat cancer cells harboring the innate and/or adaptive resistance to apoptosis induced by anticancer reagents.

We further demonstrated that Helle-mediated $G_{2} / M$ arrest was observed in not only MCF-7 but also MDA-MB-231 cells. Similarly, $\mathrm{G}_{2} / \mathrm{M}$ arrest of hepatocellular carcinoma HepG2 cells and glioblastoma U-87 cells was also induced by Helle $(12,27)$, suggesting the generality of the mechanism underlying the cytotoxicity of Helle against different types of cancer cells. Furthermore, upregulation of p21 along with the downregulation of cyclin D1, cyclin E1 and cdc25C was observed in Helle-treated MCF-7 cells. Similar alterations of some aforementioned key molecules in the regulation of cell cycle were also confirmed in Helle-treated MDA-MB-231 cells. Upregulation of p21, a central player in the regulation of cell cycle, has been involved in the $G_{2} / M$ arrest of various cancer cells induced by diverse anticancer agents including active bufadienolide compounds (12, 14, 22, 24, 43). In addition, previous reports have demonstrated that downregulation of cdc25C occurred in parallel with $\mathrm{G}_{2} / \mathrm{M}$ arrest of hepatoma and glioblastoma cells induced by Helle and Areno (12, 27, 44). Downregulation of cyclin D1 and cyclin E1 has also been involved in the $\mathrm{G}_{2} / \mathrm{M}$ arrest of prostate cancer cell lines $\mathrm{C} 4-2 \mathrm{~B}$ and DU145 induced by resveratrol combined with docetaxel (23). Moreover, an ethanol extract of a traditional Chinese medicine, Eupolyphaga sinensis Walker induced $\mathrm{G}_{2} / \mathrm{M}$ arrest of a chronic myeloid leukemia cell line K562 accompanying through downregulation of cyclin D1, cyclin E1 and cdc25C (21). Besides, the fact that the suppression of survivin expression by Helle in MCF-7 cells was in good agreement with our previous report, in which Helle induced significant downregulation of survivin along with $\mathrm{G}_{2} / \mathrm{M}$ arrest of $\mathrm{U}-87$ cells (12). Of note, $\mathrm{Li}$ et al. have also demonstrated that silencing of survivin expression causes reduced proliferation and $\mathrm{G}_{2} / \mathrm{M}$ cell cycle arrest in human cancer cells, including HeLa and MCF-7 cells (26). Collectively, our results suggested that Helle triggered $\mathrm{G}_{2} / \mathrm{M}$ arrest by modulating aforementioned key players in mitotic progression, and consequently resulted in growth inhibition of cancer cells.

A growing body of evidence has linked autophagic cell death to therapeutic efficacy of various anticancer drugs, and LC3 has been used ubiquitously as autophagy marker $(14,24,30,32,33$, 45). In agreement with these previous reports, we demonstrated the activation of AMPK, an upstream promoter of autophagy induction, and the upregulation of LC3 expression in MCF-7 cells treated with Helle. Our results also showed similar upregulation of LC3 expression in Helle-treated MDA-MB-231 cells. We further clarified that the addition of wortmannin and 3MA slightly but significantly rescued MCF-7 cells. Intriguingly, natural products, which harbor anticancer properties related to their autophagy-inducing activity, have been recently demonstrated to sensitize breast cancer cells such as MDAMB-231 cells to Taxol by inducing autophagic cell death (46, 47). Magnoflorine, a quaternary alkaloid isolated from Chinese herb, has also been demonstrated to improve the sensitivity of both MCF-7 and MDA-MB-231 cells to doxorubicin via inducing apoptosis and autophagy (48). Our results thus suggested that Helle could serve as a promising candidate of potent inducer of apoptosis and/or autophagic cell death, sensitizing breast cancer cells to conventional anticancer drugs such as Taxol and doxorubicin, although further studies will be needed to clarify the molecular details of Helle-triggered cytotoxicity in both cells.

The crosstalk between autophagy, necrosis and cell cycle arrest has received increasing attention to develop new therapeutic approaches for treatment of cancer patients (17, $35,49,50)$. In this regard, we demonstrated a close relation between autophagy and necrosis, as evidenced by a significant reduction of the numbers of PI-positive cells in MCF-7 cells when treated with Helle in the presence of wortmannin or 3-MA. We also demonstrated that Helle-triggered $\mathrm{G}_{2} / \mathrm{M}$ arrest was significantly corrected by wortmannin. Taking the previous findings and our results into account, we suggested that autophagy induction contributed to Helle-induced cytotoxicity of breast cancer cells by modulating necrosis induction and cell cycle arrest. Of note, we recently clarified that autophagy induction linked to S-phase arrest, rather than apoptosis and necrosis, in MDA-MB-231 cells treated with the combination of arsenite and tetrandrine, a Chinese plant-derived alkaloid (30, 51). Collectively, whether a correlation exists between autophagy, apoptosis/necrosis and cell cycle arrest seems to be highly dependent on different types of cancer cells and external stimuli.

\section{CONCLUSION}

Our results suggest that the generality of the mechanism underlying the cytotoxicity of Helle against both breast cancer cells is linked to its apoptosis-, $\mathrm{G}_{2} / \mathrm{M}$ arrest- and autophagyinducing activity. We further suggest potential usefulness of both 
Helle and Areno, two active bufadienolide compounds, in developing therapeutic strategies to fight against different types of breast cancer, especially ER-positive breast cancer. In addition to apoptosis induction, autophagy appeared to contribute to the cytotoxicity of Helle by modulating both necrosis and cell cycle arrest. Combined treatment has been widely used for cancer chemotherapy, aiming to maximize efficacy of anticancer drugs and minimize their undesirable side effects. In fact, Dong et al. have demonstrated that bufadienolide compounds such as gamabufotalin and bufalin sensitize human breast cancer cells to TRAIL-induced apoptosis (52). We also recently suggested that gamabufotalin could serve as a promising adjuvant therapeutic agent to potentiate therapeutic effect of arsenite in glioblastoma cells (15). The studies on cytocidal effects of conventional anticancer drugs in combination of Helle or Areno are ongoing in our laboratory.

\section{DATA AVAILABILITY STATEMENT}

The original contributions presented in the study are included in the article/Supplementary Material. Further inquiries can be directed to the corresponding authors.

\section{REFERENCES}

1. Sung H, Ferlay J, Siegel RL, Laversanne M, Soerjomataram I, Jemal A, et al. Global Cancer Statistics 2020: GLOBOCAN Estimates of Incidence and Mortality Worldwide for 36 Cancers in 185 Countries. CA Cancer J Clin (2021) 71(3):209-49. doi: 10.3322/caac.21660

2. Anastasiadi Z, Lianos GD, Ignatiadou E, Harissis HV, Mitsis M. Breast Cancer in Young Women: An Overview. Updates Surg (2017) 69(3):313-7. doi: 10.1007/s13304-017-0424-1

3. Waks AG, Winer EP. Breast Cancer Treatment: A Review. JAMA (2019) 321 (3):288-300. doi: 10.1001/jama.2018.19323

4. Dupre A, Malik HZ. Inflammation and Cancer: What a Surgical Oncologist Should Know. Eur J Surg Oncol (2018) 44(5):566-70. doi: 10.1016/ j.ejso.2018.02.209

5. Greten FR, Grivennikov SI. Inflammation and Cancer: Triggers, Mechanisms, and Consequences. Immunity (2019) 51(1):27-41. doi: 10.1016/ j.immuni.2019.06.025

6. Suarez-Carmona M, Lesage J, Cataldo D, Gilles C. EMT and Inflammation: Inseparable Actors of Cancer Progression. Mol Oncol (2017) 11(7):805-23. doi: 10.1002/1878-0261.12095

7. Qi J, Tan CK, Hashimi SM, Zulfiker AH, Good D, Wei MQ. Toad Glandular Secretions and Skin Extractions as Anti-Inflammatory and Anticancer Agents. Evid Based Complement Alternat Med (2014) 2014:312684. doi: 10.1155/2014/312684

8. Zhang X, Yuan Y, Xi Y, Xu X, Guo Q, Zheng H, et al. Cinobufacini Injection Improves the Efficacy of Chemotherapy on Advanced Stage Gastric Cancer: A Systemic Review and Meta-Analysis. Evid Based Complement Alternat Med (2018) 2018:7362340. doi: 10.1155/2018/7362340

9. Jiang Y, Liu LS, Shen LP, Han ZF, Jian H, Liu JX, et al. Traditional Chinese Medicine Treatment as Maintenance Therapy in Advanced Non-Small-Cell Lung Cancer: A Randomized Controlled Trial. Complement Ther Med (2016) 24:55-62. doi: 10.1016/j.ctim.2015.12.006

10. Zhang Y, Takagi N, Yuan B, Zhou Y, Si N, Wang H, et al. The Protection of Indolealkylamines on LPS-Induced Inflammation in Zebrafish. J Ethnopharmacol (2019) 243:112122. doi: 10.1016/j.jep.2019.112122

11. Zhang Y, Yuan B, Takagi N, Wang H, Zhou Y, Si N, et al. Comparative Analysis of Hydrophilic Ingredients in Toad Skin and Toad Venom Using the UHPLC-HR-MS/MS and UPLC-QqQ-MS/MS Methods Together With the

\section{AUTHOR CONTRIBUTIONS}

$\mathrm{BY}$ and YZ designed the study and drafted the manuscript. YZ performed the experiments. $\mathrm{BB}, \mathrm{HZ}, \mathrm{AK}, \mathrm{YI}$, and MS assisted interpretation of the results. HH and NT contributed analytical tools and discussed the results. All authors contributed to the article and approved the submitted version.

\section{FUNDING}

This work was partially supported by The Japan Society for the Promotion of Science (JSPS) KAKENHI Grant to BY (Grant Numbers 26460233) (Grant Numbers 17K08465). This study was also supported in part by grants from China Scholarship Council (file no. 201908110322).

\section{SUPPLEMENTARY MATERIAL}

The Supplementary Material for this article can be found online at: https://www.frontiersin.org/articles/10.3389/fonc.2021. $711220 /$ full\#supplementary-material

Anti-Inflammatory Evaluation of Indolealkylamines. Molecules (Basel Switzerland) (2018) 24(1):86. doi: 10.3390/molecules24010086

12. Han L, Yuan B, Shimada R, Hayashi H, Si N, Zhao HY, et al. Cytocidal Effects of Arenobufagin and Hellebrigenin, Two Active Bufadienolide Compounds, Against Human Glioblastoma Cell Line U-87. Int J Oncol (2018) 53(6):2488502. doi: 10.3892/ijo.2018.4567

13. Yuan B, He J, Kisoh K, Hayashi H, Tanaka S, Si N, et al. Effects of Active Bufadienolide Compounds on Human Cancer Cells and CD4+CD25+Foxp3+ Regulatory T Cells in Mitogen-Activated Human Peripheral Blood Mononuclear Cells. Oncol Rep (2016) 36(3):1377-84. doi: 10.3892/or.2016.4946

14. Yuan B, Shimada R, Xu K, Han L, Si N, Zhao H, et al. Multiple Cytotoxic Effects of Gamabufotalin Against Human Glioblastoma Cell Line U-87. Chem Biol Interact (2019) 314:108849. doi: 10.1016/j.cbi.2019.108849

15. Yuan B, Xu K, Shimada R, Li J, Hayashi H, Okazaki M, et al. Cytotoxic Effects of Arsenite in Combination With Gamabufotalin Against Human Glioblastoma Cell Lines. Front Oncol (2021) 11:628914. doi: 10.3389/ fonc.2021.628914

16. Deng LJ, Qi M, Peng QL, Chen MF, Qi Q, Zhang JY, et al. Arenobufagin Induces MCF-7 Cell Apoptosis by Promoting JNK-Mediated Multisite Phosphorylation of Yes-Associated Protein. Cancer Cell Int (2018) 18:209. doi: 10.1186/s12935-018-0706-9

17. Nikoletopoulou V, Markaki M, Palikaras K, Tavernarakis N. Crosstalk Between Apoptosis, Necrosis and Autophagy. Biochim Biophys Acta (2013) 1833(12):3448-59. doi: 10.1016/j.bbamcr.2013.06.001

18. Su Z, Yang Z, Xu Y, Chen Y, Yu Q. Apoptosis, Autophagy, Necroptosis, and Cancer Metastasis. Mol Cancer (2015) 14:48. doi: 10.1186/s12943-015-0321-5

19. Czabotar PE, Lessene G, Strasser A, Adams JM. Control of Apoptosis by the BCL-2 Protein Family: Implications for Physiology and Therapy. Nat Rev Mol Cell Biol (2014) 15(1):49-63. doi: 10.1038/nrm3722

20. Xu Y, Lin Z, Zhao N, Zhou L, Liu F, Cichacz Z, et al. Receptor Interactive Protein Kinase 3 Promotes Cisplatin-Triggered Necrosis in ApoptosisResistant Esophageal Squamous Cell Carcinoma Cells. PloS One (2014) 9 (6):e100127. doi: 10.1371/journal.pone.0100127

21. Dai B, Zhan Y, Qi J, Zhang Y. Eupolyphaga Sinensis Walker Inhibits Human Chronic Myeloid Leukemia Cell K562 Growth by Inducing G2-M Phase Cell Cycle Arrest and Targeting EGFR Signaling Pathway and in S180 TumorBearing Mice. Environ Toxicol Pharmacol (2014) 37(3):1177-85. doi: 10.1016/ j.etap.2014.04.010 
22. Yuan B, Yoshino Y, Kaise T, Toyoda H. Application of Arsenic Trioxide Therapy for Patients With Leukaemia. In: H Sun, editor. Biological Chemistry of Arsenic, Antimony and Bismuth. Chichester: John Wiley Sons, Ltd (2010). p. 263-92.

23. Singh SK, Banerjee S, Acosta EP, Lillard JW, Singh R. Resveratrol Induces Cell Cycle Arrest and Apoptosis With Docetaxel in Prostate Cancer Cells via a p53/p21WAF1/CIP1 and p27KIP1 Pathway. Oncotarget (2017) 8(10):1721628. doi: 10.18632/oncotarget.15303

24. Yao M, Yuan B, Wang X, Sato A, Sakuma K, Kaneko K, et al. Synergistic Cytotoxic Effects of Arsenite and Tetrandrine in Human Breast Cancer Cell Line MCF-7. Int J Oncol (2017) 51(2):587-98. doi: 10.3892/ijo.2017.4052

25. Perdiguero E, Nebreda AR. Regulation of Cdc25C Activity During the Meiotic G2/M Transition. Cell Cycle (Georgetown Tex) (2004) 3(6):733-7. doi: 10.4161/cc.3.6.906

26. Li Y, Liu D, Zhou Y, Li Y, Xie J, Lee RJ, et al. Silencing of Survivin Expression Leads to Reduced Proliferation and Cell Cycle Arrest in Cancer Cells. J Cancer (2015) 6(11):1187-94. doi: 10.7150/jca.12437

27. Deng LJ, Hu LP, Peng QL, Yang XL, Bai LL, Yiu A, et al. Hellebrigenin Induces Cell Cycle Arrest and Apoptosis in Human Hepatocellular Carcinoma HepG2 Cells Through Inhibition of Akt. Chem Biol Interact (2014) 219:184-94. doi: 10.1016/j.cbi.2014.06.003

28. Zhang DM, Liu JS, Deng LJ, Chen MF, Yiu A, Cao HH, et al. Arenobufagin, a Natural Bufadienolide From Toad Venom, Induces Apoptosis and Autophagy in Human Hepatocellular Carcinoma Cells Through Inhibition of PI3K/Akt/mTOR Pathway. Carcinogenesis (2013) 34(6):1331-42. doi: 10.1093/carcin/bgt060

29. Ishiyama M, Tominaga H, Shiga M, Sasamoto K, Ohkura Y, Ueno K. A Combined Assay of Cell Viability and In Vitro Cytotoxicity With a Highly Water-Soluble Tetrazolium Salt, Neutral Red and Crystal Violet. Biol Pharm Bull (1996) 19(11):1518-20. doi: 10.1248/bpb.19.1518

30. Yuan B, Yao M, Wang X, Sato A, Okazaki A, Komuro H, et al. Antitumor Activity of Arsenite in Combination With Tetrandrine Against Human Breast Cancer Cell Line MDA-MB-231 In Vitro and In Vivo. Cancer Cell Int (2018) 18:113. doi: 10.1186/s12935-018-0613-0

31. Kaufmann SH, Desnoyers S, Ottaviano Y, Davidson NE, Poirier GG. Specific Proteolytic Cleavage of Poly(ADP-Ribose) Polymerase: An Early Marker of Chemotherapy-Induced Apoptosis. Cancer Res (1993) 53(17):3976-85.

32. Kocaturk NM, Akkoc Y, Kig C, Bayraktar O, Gozuacik D, Kutlu O. Autophagy as a Molecular Target for Cancer Treatment. Eur J Pharm Sci (2019) 134:11637. doi: 10.1016/j.ejps.2019.04.011

33. Kabeya Y, Mizushima N, Ueno T, Yamamoto A, Kirisako T, Noda T, et al. LC3, a Mammalian Homologue of Yeast Apg8p, Is Localized in Autophagosome Membranes After Processing. EMBO J (2000) 19(21):57208. doi: $10.1093 / \mathrm{emboj} / 19.21 .5720$

34. Chiacchiera F, Simone C. The AMPK-FoxO3A Axis as a Target for Cancer Treatment. Cell Cycle (Georgetown Tex) (2010) 9(6):1091-6. doi: 10.4161/cc.9.6.11035

35. Amaravadi RK, Thompson CB. The Roles of Therapy-Induced Autophagy and Necrosis in Cancer Treatment. Clin Cancer Res (2007) 13(24):7271-9. doi: 10.1158/1078-0432.Ccr-07-1595

36. Qin L, Liao L, Redmond A, Young L, Yuan Y, Chen H, et al. The AIB1 Oncogene Promotes Breast Cancer Metastasis by Activation of PEA3Mediated Matrix Metalloproteinase 2 (MMP2) and MMP9 Expression. Mol Cell Biol (2008) 28(19):5937-50. doi: 10.1128/mcb.00579-08

37. Torres-Arzayus MI, Font de Mora J, Yuan J, Vazquez F, Bronson R, Rue M, et al. High Tumor Incidence and Activation of the PI3K/AKT Pathway in Transgenic Mice Define AIB1 as an Oncogene. Cancer Cell (2004) 6(3):26374. doi: 10.1016/j.ccr.2004.06.027

38. Alkner S, Bendahl PO, Grabau D, Lövgren K, Stål O, Rydén L, et al. AIB1 Is a Predictive Factor for Tamoxifen Response in Premenopausal Women. Ann Oncol (2010) 21(2):238-44. doi: 10.1093/annonc/mdp293

39. Osborne CK, Bardou V, Hopp TA, Chamness GC, Hilsenbeck SG, Fuqua SA, et al. Role of the Estrogen Receptor Coactivator AIB1 (SRC-3) and HER-2/ Neu in Tamoxifen Resistance in Breast Cancer. J Natl Cancer Inst (2003) 95 (5):353-61. doi: 10.1093/jnci/95.5.353
40. Wang Y, Lonard DM, Yu Y, Chow DC, Palzkill TG, Wang J, et al. Bufalin Is a Potent Small-Molecule Inhibitor of the Steroid Receptor Coactivators SRC-3 and SRC-1. Cancer Res (2014) 74(5):1506-17. doi: 10.1158/0008-5472.Can13-2939

41. Wang $\mathrm{T}, \mathrm{Mu} \mathrm{L}$, Jin $\mathrm{H}$, Zhang $\mathrm{P}$, Wang $\mathrm{Y}, \mathrm{Ma} \mathrm{X}$, et al. The Effects of Bufadienolides on HER2 Overexpressing Breast Cancer Cells. Tumour Biol (2016) 37(6):7155-63. doi: 10.1007/s13277-015-4381-3

42. Gong Y, Fan Z, Luo G, Yang C, Huang Q, Fan K, et al. The Role of Necroptosis in Cancer Biology and Therapy. Mol Cancer (2019) 18(1):100. doi: 10.1186/ s12943-019-1029-8

43. Das CM, Aguilera D, Vasquez H, Prasad P, Zhang M, Wolff JE, et al. Valproic Acid Induces P21 and Topoisomerase-II (Alpha/Beta) Expression and Synergistically Enhances Etoposide Cytotoxicity in Human Glioblastoma Cell Lines. J Neurooncol (2007) 85(2):159-70. doi: 10.1007/s11060-0079402-7

44. Deng LJ, Peng QL, Wang LH, Xu J, Liu JS, Li YJ, et al. Arenobufagin Intercalates With DNA Leading to G2 Cell Cycle Arrest via ATM/ATR Pathway. Oncotarget (2015) 6(33):34258-75. doi: 10.18632/oncotarget.5545

45. Tanida I, Ueno T, Kominami E. LC3 and Autophagy. Methods Mol Biol (Clifton NJ) (2008) 445:77-88. doi: 10.1007/978-1-59745-157-4_4

46. Lee Y, Na J, Lee MS, Cha EY, Sul JY, Park JB, et al. Combination of Pristimerin and Paclitaxel Additively Induces Autophagy in Human Breast Cancer Cells via ERK1/2 Regulation. Mol Med Rep (2018) 18(5):4281-8. doi: 10.3892/ mmr.2018.9488

47. Li T, Zhang S, Chen F, Hu J, Yuan S, Li C, et al. Formononetin Ameliorates the Drug Resistance of Taxol Resistant Triple Negative Breast Cancer by Inhibiting Autophagy. Am J Trans Res (2021) 13(2):497-514.

48. Wei T, Xiaojun X, Peilong C. Magnoflorine Improves Sensitivity to Doxorubicin (DOX) of Breast Cancer Cells via Inducing Apoptosis and Autophagy Through AKT/mTOR and P38 Signaling Pathways. BioMed Pharmacother (2020) 121:109139. doi: 10.1016/j.biopha.2019.109139

49. Mathiassen SG, De Zio D, Cecconi F. Autophagy and the Cell Cycle: A Complex Landscape. Front Oncol (2017) 7:51. doi: 10.3389/fonc.2017.00051

50. Zheng K, He Z, Kitazato K, Wang Y. Selective Autophagy Regulates Cell Cycle in Cancer Therapy. Theranostics (2019) 9(1):104-25. doi: 10.7150/thno.30308

51. Yu B, Yuan B, Li J, Kiyomi A, Kikuchi H, Hayashi H, et al. JNK and Autophagy Independently Contributed to Cytotoxicity of Arsenite Combined With Tetrandrine via Modulating Cell Cycle Progression in Human Breast Cancer Cells. Front Pharmacol (2020) 11:1087. doi: 10.3389/ fphar.2020.01087

52. Dong Y, Yin S, Li J, Jiang C, Ye M, Hu H. Bufadienolide Compounds Sensitize Human Breast Cancer Cells to TRAIL-Induced Apoptosis via Inhibition of STAT3/Mcl-1 Pathway. Apoptosis (2011) 16(4):394-403. doi: 10.1007/s10495011-0573-5

Conflict of Interest: The authors declare that the research was conducted in the absence of any commercial or financial relationships that could be construed as a potential conflict of interest.

Publisher's Note: All claims expressed in this article are solely those of the authors and do not necessarily represent those of their affiliated organizations, or those of the publisher, the editors and the reviewers. Any product that may be evaluated in this article, or claim that may be made by its manufacturer, is not guaranteed or endorsed by the publisher.

Copyright $(2021$ Zhang, Yuan, Bian, Zhao, Kiyomi, Hayashi, Iwatani, Sugiura and Takagi. This is an open-access article distributed under the terms of the Creative Commons Attribution License (CC BY). The use, distribution or reproduction in other forums is permitted, provided the original author(s) and the copyright owner(s) are credited and that the original publication in this journal is cited, in accordance with accepted academic practice. No use, distribution or reproduction is permitted which does not comply with these terms. 